\title{
THE HUMAN FACTOR IN TRAFFIC ACCIDENTS*
}

\author{
Prof. Dr. Cevat Geray \\ Dean, Faculty of Political Sciences. \\ Ankara University
}

\section{Introduction}

In the last fifteen years there has been a large increase in the number of motor vehicles in Turkey. It is quite recent that we are entering into the epoque of motor-cars. Nevertheless Turkey is annually renewing her own record of traffic accidents and loss of life and property due to it. The caos or anarchy of traffic keeps on spreading death on our roads. Turkey is the country where the average rate of death or injured per vehicle is highest.

The human factor lies in the very root of traffic accidents in our country. Actually, out of every 10 accidents, 7 are due to drivers, 2 to pedestrians and only one is due to vehicle or road. Thus, when examining the traffic accidents it is especially relevant to emphasize the education process which aims at changing human behaviour, thought, knowledge, talent and values of mankind.

The number of motor vehicles in Turkey is constantly incereasing. It is certain that besides general factors such as the horizontal mobility in society, urbanization, industrialization, production for market, the effects of an externally dependent road transportation, a policy of transportation based on private car ownership and an assebly industry which feeds it must not be underestimated. During the 25 year period of 1950-1975, while the total amount of motor vehicles increased by 20 times, cars increased by 30 times, trucks by 9 times and buses by 7 times. During the period of 1960-1976, the rate of increase in the number of accidents is higher than $(633 \%)$ the rate of increase in the number of vehicles $(541 \%)$. There is an increase in smaller amounts in the deaths and injuries due to traffic accidents (353-385 $\%)$. But comparison reveals that Turkey by far exceeds other countries

- Paper presented at the III rd International Conference on Traffic Problems and Traffic Accidents, held in Ankara, on 8-10 11 September 1980. 
in rates of accidents, deaths and injuries. According to data for 1976, in specific countries, the number of accidents per 10 thousand vehicles is as follows: United States of America 88, France 107, Sweden 55, Italy 76, Spain 87, Poland 108, Portugal 286, Greece 111, Yugoslavia 195 and Turkey 208. Turkey takes the second place after Portugal. But in rates concerning death and injuries per vehicles Turkey takes the leading place. It has the highest death rate per 10 thousand vehicles. While in Turkey 48 deaths occur per every 10 thousand vehicles, this rate is 3 in the U.S.A., 4 in Sweden and Italy, 6 in France and Spain, 13 in Greece, 16 in Poland, 22 in Portugal. In the ten years between 1968-1976 there have been significant decreases in this respect. This is due to the fact that deaths taking place in the days following the accidents are not recorded in relavant statistics. Otherwise results would be even more depressing.

When the number of vehicles and length of roads are taken into consideration, Turkey takes second place after Yugoslavia in number of deaths. But she has a. relatively low number of injuries.

\section{Causes of Accidents}

It is clear that accidents are largely due to drivers and pedestrians in Turkey. Accidents due to roads are about $10 \%$. Whereas the human factor such as driver, pedestrian or passenger at fault is $90 \%$. When a long period of time (1955-1974) is taken into consideration, no significant change can be seen in these rates.

\section{Faults of Drivers}

Among accidents due to faults of drivers, violations of regulations and signs and non-licensed driving takes first place with a rate of $66 \%$. Fast driving holds second place with a rate of $23 \%$, and recklessness, fatigue and sleeplessness take third place with $9 \%$. While there is a decrease in accidents due to recklessness, fatigue and seeplessness, there is an increase in accidents due to violations of regulations, signs and non-licensed driving.

\section{Faults of Pedestrians}

Among faults of pedestrians involved in accidents, sudden appearances on the roads, jay walking, playing and sitting on roads holds the first place $(56.8 \%)$. The second place is occupied by road crossings contrary to regulations ( $35.2 \%)$. A cause of accidents worth noting 
is untimely jumpings or descendings from vehicles. Another cause of accidents with a rate of $4 \%$ is due to drunken pedestrians.

\section{Accidents Due to Vehicles and Roads}

The accidents due to vehicles and roads are much less than the accidents due to the human factor. Reasons for this are that the planners, the builders, the users and the repairers of the roads and vehicles are equipped with the necessary knowledge and skill. They take the utmost care; they are always alert and they obey the rules. These greatly contribute to reduce the death toll, injuries and material damage. Shortly, there is always the human factor with its visible and invisible effects behind the vehicle and road factors.

\section{Drunkenness and Traffic Accidents}

It is not easy to predict the real reasons which lie in the root of faults of the drivers and pedestrians who are involved in accidents. Thus, the rates concerning drunkenness are low in statistics. In fact, the main reason for recklessness, fatigue and violation of rules, is drunkenness. Alcohol, while driving affects reactions and vision. It causes a gap between hearing and acting, it increases the individual's self-confidence to a dangerous extent, and it encourages speed, distracts attention and reduces the visual ability. A driver whose blood contains more than 1.5 in a thousand of alcohol, is 55 times more likely to have an accident compared to a driver who has no alcohol.

In Henepin, Minnesota, U.S.A., due to measures taken against drunken drivers in the year 1971, a great decrease had been observed in traffic offenses in 1975 and this had reduced the expenses by $10 \%$.

In various countries, it is a crime to drive while one is under the influence of alcohol. There is a relation between the habit of alcohol usage and social and economic problems.

Alcoholism is a grave habit. Therefore, it cannot be prevented only by educational efforts. Security control should be enforced by medical measures.

\section{The Level of Knowledge of Drivers}

It is quite difficult to determine to what extent an accident is due to a driver's lack of knowledge or to his reluctance in obeying rules. All the same it can be argued that drivers who do not stick to traffic 
regulations do not know or recognize relevant symbols or signs when they see them.

\section{Social Factors}

No significant research has been done on the role that social factors have in human behaviour which leads to traffic accidents. It is obvious that human behaviour is a function of the social and economic environment the individual is situated in. Respect for civic rules, human life including one's own are not attitudes, values or behaviour that can easily be changed only by educational measures and security enforcement. The cities and towns that have been founded for pedestrians and horse carriages have not yet been adapted to the age of engines. Our people are not yet oriented to the necessities of the motor age. Moreover, we must admit that a social order which justifies corruption is reflected in road traffic. Besides, the motor age can fulfill the social benefits expected from this technology only by means of social control. But on the other hand, it is natural that selfish and egotistic behaviour is reflected on traffic in a society where unfair manners and quickest ways of acquiring wealth and success are permitted, even encouraged to a great extent. This leads to weak enforcement of rules and anomy in civic life in general.

\section{What Sort of Traffic Education}

Education is the process of the creation of change in the knowledge, competence, behaviour, ideas and values of human beings. It helps the individual to develop his physical, spiritual capacities and thereby to participate in social, economic and political processes, to adapt to the natural and social environment as well as to change them. The aim of traffic education is to endow the individual with necessary knowledge, competence, thought, behaviour and values which will lead him to participate in the process and flow of traffic in the most proper manner.

The content of traffic education has to cover all the necessary topics for ensuring the safest and most economic implementation of stationary and moving traffic. Everyone participating in traffic in his capacity as pedestrian, passenger or driver, and people with jobs in related areas of engineering and security activities, must undergo a thorough education which includes information about proper ways of using roads, parking areas, sidewallks, infranstructure under and near roads, symbols, proper ways of driving various vehicles, all rules and regulations and related technology. 
In our country traffic education is insufficient. There are some efforts of a small number of voluntary associations which do not have any formal public identity. On the other hand, relevant governmental offices lack serious coordination and cooperation between them. Moreover, the formation of public opinion via mass media is discontinuous and irregular.

In our view, campaigns of traffic education should be started and a common national programme of traffic training developed. Relevant public offices and voluntary associations should participate in these efforts. All means should be employed with common aims for specialized public training and education.

\section{Conclusion}

As a society with its pedestrians, drivers and passengers, we have not yet acquired the knowledge, competence and behaviour the motor age requires. In other words, we do not pay due attention to give the necessary education to our people to adapt to the age. As a result of this, everyone involved in traffic is a potential threat to human life. Although the cause of traffic accidents cannot be reduced to one factor, we may say that there is a negative correlation between the probability of having accidents and the level of civic education. Nevertheless, countries with a high level of education, still have very high rates of accidents. Therefore, traffic education should occupy a specia] place in curricula at all levels of school and adult education. It should be emphasized here that the press, radio and television have a special role in ensuring this. Also, radical changes should be brought about in the procedures for getting driving licenses. The training of drivers should not be left to private enterprise, as a matter of profit making. Instead the goverment must establish public schools for driving. 